Fiqih Zetrita Putri, Aldri Frinaldil Efektivitas Rujukan Online bagi Pasien Rawat Jalan dalam Program Jaminan Kesehatan Nasional (JKN) di Kota Solok

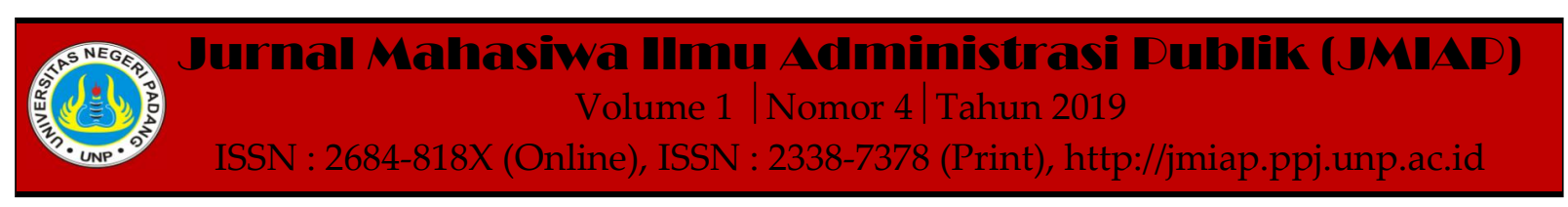

\title{
EFEKTIVITAS RUJUKAN ONLINE BAGI PASIEN RAWAT JALAN DALAM PROGRAM JAMINAN KESEHATAN NASIONAL (JKN) DI KOTA SOLOK
}

\author{
Fiqih Zetrita Putri ${ }^{1(a)}$, Aldri Frinaldi ${ }^{2(b)}$ \\ ${ }^{1}$ Jurusan Ilmu Administrasi Negara, Universitas Negeri Padang \\ ${ }^{2}$ Jurusan Ilmu Administrasi Negara, Universitas Negeri Padang \\ a)fiqihzetrita24@gmail.com, ${ }^{b}$ aldrifrinaldi@gmail.com
}

\begin{abstract}
This study aims to determine the effectiveness of online referrals for outpatients in the National Health Insurance Program (JKN) in the city of Solok and describe the constraints and efforts that realize the effectiveness of online referrals for outpatients in the city of Solok. This research is motivated by the obstacles in FKTP as well as complaints from participants or the community when the online referral system was implemented. This research uses a qualitative method with a descriptive approach. The instrument of data collection was through interviews, observations and documentation. The results of this study were the effectiveness of online referrals in the national health insurance program in the city of Solok. It was not effective because there were still some obstacles, both constraints from BPJS, FKTP, FKRTL and also complaints felt by the participants.
\end{abstract}

Keywords : Effectivennes of Online Referrals, National Health Insurance, Administrative Services Health

Corresponding author. Email.fiqihzetrita24@gmail.com,aldrifrinaldi@gmail.com

How to cite this article. Putri, F. Zetrita \& Frinaldi, A. (2019). Efektivitas Rujukan Online bagi Pasien Rawat Jalan dalam Program Jaminan Kesehatan Nasional (JKN) di Kota Solok. Jurnal Mahasiwa Ilmu Administrasi Publik (JMIAP) Jurusan Ilmu Administrasi Negara Fakultas Ilmu Sosial Universitas Negeri Padang, Volume 1 (4), Hal. 28-38.

http://jmiap.ppj.unp.ac.id

ISSN : 2684-818X (Online), ISSN : 2338-7378 (Print)

Copyright $@ 2019$. Published by Pusat Kajian-Pemberdayaan dan Pelayanan Masyarakat (PK-P2M) FIS UNP Padang 
Fiqih Zetrita Putri, Aldri Frinaldil Efektivitas Rujukan Online bagi Pasien Rawat Jalan dalam Program Jaminan Kesehatan Nasional (JKN) di Kota Solok

\section{PENDAHULUAN}

Badan penyelenggara jaminan sosial kesehatan sebagai pelaksana merupakan badan hukum publik yang dibentuk untuk menyelenggarakan program jaminan kesehatan bagi seluruh rakyat Indonesia. Jaminan kesehatan merupakan jaminan kesehatan berupa perlindungan kesehatan agar peserta jaminan kesehatan memperoleh manfaat dari adanya pemeliharaan kesehatan serta perlindungan dalam memenuhi kebutuhan dasar kesehatan yang diberikan kepada setiap peserta yang telah membayar iuran atau iurannya sudah dibayarkan oleh pemerintah daerah maupun pemerintah pusat.

Sesuai dengan amanat undang-undang tahun No 24 tahun 2011 yang mana undangundang ini yang melatarbelakangi rujukan online dan juga undang-undang No 82 tahun 2018 serta peraturan presiden. Pada undang-undang No 24 tahun 2011 tentang Badan Penyelenggara Jaminan Sosial di amanatkan bahwa BPJS kesehatan sebagai penyelenggra program Jaminan Kesehatan Nasional (JKN) itu diberikan kewenangan dalam mengembangkan teknis operasionalitas sistem pelayanan kesehatan, salah satu teknik operasionlitas sistem pelayanan kesehatan ini adalah sistem rujukan online.

Rujukan online merupakan proses digitalisasi rujukan berjenjang yang diberikan kepada pasien atau masyarakat untuk mendapatkan kemudahan serta kepastian peserta dalam memperoleh pelayanan kesehatan dirumah sakit atau fasilitas kesehatan rujukan tingkat lanjut (FKRTL). pelayanan yang diberikan kepada pasien dalam sistem rujukan online ini yaitu pelayanan rawat jalan, pelayanan rawat inap dan pelayanan gawat darurat.. Rawat jalan merupakan bentuk pelayanan yang diberikan kepada pasien untuk pengobatan, observasi, mendiagnosis penyakitnya serta untuk rehabilitasi medis dan pelayanan kesehatan lain tanpa harus menginap dirumah sakit. Keuntungan bagi pasien rawat jalan ini adalah pasien tidak perlu mengeluarkan biaya untuk menginap dirumah sakit.

Tabel 1. Jumlah Rujukan Online di Puskesmas Kota Solok pada Bulan Agustus 2018 Sampai Dengan Bulan September 2019

\begin{tabular}{|c|c|c|c|}
\hline \multirow{2}{*}{ Tahun } & \multirow{2}{*}{ Bulan } & \multicolumn{2}{|c|}{ Jumlah Rujukan } \\
\hline & & Puskesmas Tanah Garam & Puskesmas Tanjung Paku \\
\hline \multirow{5}{*}{2018} & Agustus & 374 & 254 \\
\hline & September & 348 & 287 \\
\hline & Oktober & 398 & 342 \\
\hline & November & 371 & 278 \\
\hline & Desember & 350 & 275 \\
\hline \multirow{9}{*}{2019} & januari & 428 & 351 \\
\hline & Februari & 434 & 280 \\
\hline & Maret & 434 & 280 \\
\hline & April & 388 & 292 \\
\hline & Mei & 357 & 250 \\
\hline & Juni & 324 & 266 \\
\hline & Juli & 479 & 408 \\
\hline & Agustus & 409 & 311 \\
\hline & September & 364 & 313 \\
\hline
\end{tabular}

Sumber Data : BPJS Kesehatan Cabang Solok 
Fiqih Zetrita Putri, Aldri Frinaldi| Efektivitas Rujukan Online bagi Pasien Rawat Jalan dalam Program Jaminan Kesehatan Nasional (JKN) di Kota Solok

\begin{tabular}{|c|c|c|c|}
\hline \multirow{2}{*}{ Tahun } & \multirow{2}{*}{ Bulan } & \multicolumn{2}{|c|}{ Jumlah Rujukan } \\
\hline & & PuskesmNan Balimo & Puskesmas KTK \\
\hline \multirow{5}{*}{2018} & Agustus & 95 & 213 \\
\hline & September & 100 & 220 \\
\hline & Oktober & 137 & 245 \\
\hline & November & 106 & 239 \\
\hline & Desember & 109 & 240 \\
\hline \multirow{9}{*}{2019} & januari & 128 & 292 \\
\hline & Februari & 91 & 217 \\
\hline & Maret & 91 & 217 \\
\hline & April & 138 & 245 \\
\hline & Mei & 114 & 217 \\
\hline & Juni & 110 & 173 \\
\hline & Juli & 146 & 272 \\
\hline & Agustus & 120 & 249 \\
\hline & September & 119 & 251 \\
\hline
\end{tabular}

Sumber Data : BPJS Kesehatan Cabang Solok

Dari table diatas dapat dilihat bahwa sistem Rujukan Online ini mulai diterapkan pada bulan Agustus 2018 sampai saat sekarang. Sistem rujukan online diterapkan pada Fasilitas Kesehatan Tingkat Pertama (FKTP) yaitu puskesmas yang kemudian dilanjutkan ke Fasilitas Kesehatan Rujukan Tingkat Lanjut (FKRTL) yaitu Rumah Sakit. Yang mana Dikota Solok, sistem rujukan online diterapkan pada 4 puskesmas yaitu : Puskesmas Tanah Garam, Puskesmas Tanjung Paku, Puskesmas Nan Balimo dan Puskesmas KTK.

Belum efektifnya sistem rujukan online dikota solok dapat dilihat dari beberapa permasalahan yang terjadi saat menerapkan sistem rujukan online ini yaitu :kendala yang ditemui oleh BPJS Kesehatan kota solok yaitu kendala dari masyarakat yang agak susah mengembalikan mindset atau pola pikir peserta tentang rujukan online ini. Kendala dari jaringan saat proses rujukan berlangsung yang dapat mengganggu peserta pada saat proses rujukan yang mengakibatkan peserta harus menunggu untuk beberapa waktu.kendala dari FKRTL yaitu pasien yang dirujuk terkadang tidak sesuai dengan penyakit yang dialaminya. Serta keluhan yang dirasakan oleh peserta seperti masih menunggu antrian yang lama diakibatkan karena dokter atau tenaga medis yang akan melayaninya kurang memadai dibandingkan dengan banyaknya peserta yang dirujuk dan juga peserta yang tidak bisa memilih tempat rujukan secara langsung karena rujukan ditentukan oleh aplikasi.

Berdasarkan latar belakang masalah diatas, maka penulis melakukan penelitian di kota solok mengenai Efektivitas Rujukan Online Dalam Program Jaminan Kesehatan Nasional Untuk Meningkatkan Kualitas Pelayanan Administrasi Kesehatan Di Kota Solok, Rumusan Masalah yang dikemukakan dalam penelitian ini adalah : 1) Bagaimana Efektivitas Rujukan Online Untuk Meningkatkan Kualitas Pelayanan Administrasi Kesehatan Di Kota Solok?, 2) Faktor penghambat atau kendala yang ditemui Dalam Efektivitas Rujukan Untuk Meningkatkan Kualitas Pelayanan Administrasi Kesehatan Di Kota Solok?, 3) Upaya Yang Dilakukan Untuk Mengatasi Kendala Dalam Efektivitas Rujukan Online. Untuk Meningkatkan Kualitas Pelayanan Administrasi Kesehatan Di Kota Solok. 


\section{TINJAUAN PUSTAKA}

\section{Konsep Efektivitas}

a) Efektivitas Program

Efektivitas menurut Sadarmayanti (dalam Anas, 2018:1312) mengungkapkan bahwa efektivitas merupakan suatu ukuran yang dapat memberikan gambaran terhadap seberapa jauh tujuan atau target yang dapat tercapai. Makmur (dalam Anas, 2018:1312) menjelaskan bahwa efektivitas adalah penyelesaian pekerjaan atau tugas tepat pada waktunya yang sudah ditentukan sebelumnya. Maksudnya bahwa dalam menyelesaikan suatu pekerjaan yang sudah ditentukan sebelumnya dapat dilakukan dengan cara bagaimana pelaksanaannya dan juga biaya yang akan dikeluarkan untuk menyelesaikan pekerjaan tersebut.

Efektivitas Program merupakan suatu cara yang dilakukan untuk mengukur sejauh mana program tersebut dapat berjalan sebelumnya. Efektivitas program dapat diketahui dengan cara membandingkan tujuan program dengan output atau hasil program (satries dalam pertiwi:). Suatu program dapat dikatakan efektif apabila tujuan dari program tersebut dapat tecapai dan ada output atau hasilnya, dan juga apabila suatu program itu dapat dikatakan efektif apabila dengan adanya program tersebut aka nada dampak atau perubahan nya secara nyata.

\section{b) Karakteristik Efektivitas}

Sutrisno (dalam pertiwi:4) menjelaskan bahwa untuk mengukur efektivitas program dapat dilihat dari beberapa indikator sebagai berikut :

1. Pemahaman Program : yaitu dapat dilihat dari sejauhmana masyarakat dapat memahami kegiatan program yang dilaksanakan tersebut.

2. Tepat Sasaran : yaitu dapat dilihat dari sejauhmana apa yang dikehendaki tercapai atau menjadi kenyataan. Maksudnya bahwa bahwa dalam pelaksanaan program agar tepat sasaran itu bisa dilihat dari sasaran program yang ditentukan sebelumnya.

3. Tepat Waktu : yaitu dapat dilihat melalui penggunaan waktu yang digunakan untuk pelaksanaan program yang sudah direncanakan tersebut, apakah sudah sesuai dengan apa yang diharapkan atau belum.

4. Tercapainya Tujuan : yaitu dapat diukur melalui pencapain tujuan kegiatan yang sudah dijalankan. Maksudnya bahwa dalam membuat program harus ada tujuan yang ditentukan agar program yang dibuat tersebut dapat menghasilkan output dari program tersebut.

5. Perubahan Nyata : yaitu dapat diukur dari sejauh mana kegiatan tersebut memberikan dampak atau efek serta perubahan yang nyata bagi masyarakat ditempat. Suatu program akan berdampak bagi pengguna maupun pelaksana dari program tersebut.

\section{Konsep Jaminan Kesehatan Nasional (JKN)}

a) Badan Penyelenggara Jaminan Sosial (BPJS) Kesehatan

Badan penyelenggara jaminan sosial merupakan badan hukum atau lembaga yang secara khusus menyediakan program jaminan kesehatan untuk masyarakat indonesia. Badan Penyelenggara Jaminan Sosial (BPJS) Kesehatan merupakan badan penyelenggara program pemerintah sebagai wujud untuk melaksanakan kewajiban negara dalam memastikan serta untuk menjamin masyarakat atau pesertaJKN-KIS dapat memperoleh haknya untuk hidup sehat. Dengan adanya badan penyelenggara jaminan sosial ini masyarakat akan mendapatkan jaminan kesehatan yang pasti untuk dapat menikmati manfaat dari penanganan kesehatan yang berkelanjutan dan luas.

b) Jaminan Kesehatan Nasional

Jaminan kesehatan adalah upaya yang dilakukan oleh pemerintah untuk menjamin 
dan memastikan kesehatan seluruh masyarakat Indonesia secara bermutu, komprehensif, terjangkau, dan murah melalui sistem rujukan yang berjalan dengan baik Primasari (2015:79). Jaminan Kesehatan Nasional ini merupakan bagaian dari sistem jaminan nasional yang diselenggarakn dengan menggunakan mekanisme asuransi kesehatan yang bersifat wajib berdasarkan undang-undang Nomor 40 Tahun 2004 tentang sistem jaminan sosial nasional yang bertujuan untuk agar dapat memenuhi kebutuhan kesehatan masyarakat yang layakyang diberikan kepada setiap orang. Sedangkan tujuan diadakannya program jaminan kesehatan ini adalah dapat memberikan pelayanan dibidang kesehatan secara perorangan yang komprehensip meliputi : pelayanan preventif, promotif, dan juga rehabilitative, serta juga termasuk obat dan bahan medis.

\section{c) Rujukan Online}

Rujukan online merupakan proses digitalisasi rujukan secara berjenjang agar memberikan kepastian dan kemudahan masyarakat atau peserta untuk memperoleh layanan dirumah sakit yang disesuaikan dengan jarak, kapasitas, dan kompetisi rumah sakit tempat rujukan berdasarakan kebutuhan medis yang dibutuhkan pasien. Yang tujuannya untuk dapat meningkatkan kualitas pelayanan administrasi di fasilitas kesehatan.

\section{d) Puskesmas}

Pusat kesehatan masyarakat atau yag disingkat puskesmas adalah upaya pelayanan kesehatan pertama yang memiliki kewajiban dalam memberikan upaya pelayanan kesehatan dasar kepada masyarakat yang membutuhkan, Wardani (2014, vol 03 No 04). Selain itu puskesmas bisa juga diartikan sebagai fasilitas pelayanan kesehatan bagi masyarakat yang menyelenggarakan upaya kesehatan kepada masyarakat dan juga kesehatan secara perseorangan tingkat pertama, dengan lebih mengutamakan upaya preventif, promotif agar dapat mencapai derajat kesehatan masyarakat yang setinggi-tingginya diwilayah kerjanya.

e) Rumah Sakit

Dalam undang-undang No 44 Tahun 2009 pada pasal 1 ayat 1 menjelaskan bahwa rumah sakit adalah institusi pelayanan kesehatan yang menyelenggarakan pelayanan kesehatan perorangan secara paripurna yang menyediakan pelayanan rawat inap, rawat jalan, dan gawat darurat. Rumah sakit memiliki tugas yaitu untuk melaksanakan upaya kesehatan serta berdaya guna dan berhasil guna dengan mengutamakan upaya penyembuhan dan pemulihan yang dilaksanakan secara serasi dan terpadu dengan upaya rujukan. Selain itu ruah sakit juga memiliki fungsi seperti pendidikan, penelitian, dan perawatan.

\section{f) Primary Care}

Primary Care adalah aplikasi yang digunakan oleh petugas puskesmas atau dokter di fasilitas kesehatan tingkat pertama untuk mengentry data atau pengecekan data peserta atau pasien yang mendaftar rujukan. Pada aplikasi ini petugas akan mengisi riwayat penyakit peserta serta pengobatan dari seluruh pendaftar. Aplikasi ini bertujuan agar memberikan kemudahan kepada peserta atau pendaftaran, terapi obatan, penegakan diagnosis, dan pelayanan laboratorium.

\section{g) Elektronik Government}

Elektronik Government adalah pemakaian atau penggunaan teknologi informasi yang digunakan oleh pemerintah untuk mengkomunikasikan, mengumpulkan, menyebarkan informasi guna untuk meningkatkan hubungan antara pemerintah dengan pihak lain.

\section{METODE PENELITIAN}

Penelitian ini menggunakan metode kualitatif dengan pendekatan deskriptif. Penelitian ini dilakukan di Kota Solok yaitu pada Badan Penyelenggara Jaminan Sosial (BPJS) Keshatan Kota Solok, Puskesmas 
Kota Solok, dan Rumah Sakit Kota Solok. Informan penelitian ditentukan dengan carapurposive sampling. Sehingga yang menjadi informan dalam penelitian ini adalah : Kepala Bidang Penjaminan Manfaat Primer (BPJS) Kesehatan Cabang Kota Solok, Staf P Care Kesehatan Puskesmas Tanah Gara, Staf P Care Kesehatan Puskesmas Tanjung Paku, Staf P Care Kesehatan Pusksmas Nan Balimo dan Pra Penyelihan Puskesmas KTK, Kepala Instalasi RSUD Muhammat Natsir Kota Solok, dan peserta Rujukan Online sebanyak 5 orang. Data yang digunakan dalam penelitian ini adalah data primer dan sekunder. Pengumpulan data dilakukan dengan cara wawancara, observasi dan studi Dokumentasi dengan uju keabsahan data trianggulasi sumber. Sedangkan untuk teknik analisis data dilakukan dengan cara redukasi data, penyediaan data dan penarikan kesimpulan.

\section{HASIL DAN PEMBAHASAN}

Dalam penelitian ini peneliti menggunakan teori efektivitas program yang dikembangkan oleh Sutrisno (dalam pertiwi:4) untuk mengukur tingkat efektivitas suatu program. Teori tersebut digunakan dan dikembangkan berdasarkan kebutuhan penelitian dan karakteristik efektivitas program rujukan online dalam program jaminan kesehatan nasional (JKN) Di Kota Solok. Adapun karakteristik ataupun indicator didalam efektivitas program rujukan online adalah: pemahaman Program, Tepat Sasaran, Tepat Waktu, Tercapainya Tujuan, dan Perubahan Nyata.

\section{Pemahamn Program}

Untuk melihat sejauh mana masyarakat atau peserta dapat memahami kegiatan dari program tersebut, dapat dilihat dari ungkapan yang pendapat EVD (Kepala Bidang Penjaminan Manfaat Primer (PMP) BPJS Kesehatan cabang kota solok) mengungkapkan ;

"dalam mensosialisasikan program
rujukan online ini kami
mengundang seluruh stake holder

BPJS Kesehatan baik itu FKTP maupun FKRTL, dan juga kita mengundang asosiasi faskes, organisasi provinsi, Mutu Kendali Biaya, seluruh kepala dinas kesehatan. Kemudian kami jelaskan bagaimana alur dari rujukan online ini serta konsep dari rujukan online yang berbasis kompetensi. Sosialisasi ini kami lakukan dengan cara mengumpulkan seluruh stake holder yang terkait dan juga sosialisasi lewat radio, melalui talkshow diradio dan juga berita penyiaran lewat radio, selanjutnya kami juga mensosialisasikan dengan cara Goes To Costumer yaitu turun langsung ke masyarakat. Selain cara itu kami juga mensosialisasikan rujukan online ini dengan cara PIL namanya yaitu Pemberian Informasi Langsung ke masyarakat. Kami melakukan sosialisasi itu secara bertahap dari bulan agusut sampai akhir tahun 2018 atau 5 bulan kurang lebih. Selain dari sosialisasi kami juga melakukan feedback dan pemantauan keseluruh stake holder baik FKTP maupun FKRTL untuk melihat apakah system ini berjalan dengan lancar. Kendala yang kami temukan pada saat awal awal sistem ini dijalankan yaitu masih banyaknya masyarakat kita yang belum paham tentang alur rujukan online ini dan begitu juga dengan FKTP dan FKRTL nya, namun seiring berjalannya waktu masyarakat maupun FKTP dan FKRTL nya sudah mulai paham dengan rujukan online ini”. (wawancara, 08 Oktober 2019).

Kemudian CA (Staf P Care Kesehatan Puskesmas Nan Balimo) mengungkapkan :

"System rujukan online ini sudah diberikan sosialisasi oleh orang BPJS yang berbasisi kompetensi 
melaui pertemuan langsung dan juga melalui poster dan juga surat. Namun kendala pada awal-awal pelaksanaan rujukan online itu masih kurang pahamnya masyarakat mengenai alur rujukan online ini". (wawancara, 10 Oktober 2019).

Begitu pula M (Kepala Instalasi Rekam Medis RSUD Muhammat Natsir Kota Solok) mengungkapkan bahwa :

"Pasien sudah paham dengan
prosedur yang ada bagaimana
dengan alur rujukan online ini,
begitu juga dengan petugas rekam
medis nya mereka sudah paham,
karena rujukan online ini kan
berbasis aplikasi jadi petugas
cuman mengentry data pasien aja
lagi ke aplikasi, tetapi pada saat
awal-awal dulu ya masih ada yang
kurang paham petugasnya tetapi
diberikan sosialisasi terus menerus
oleh pihak BPJS". (wawancara, 08
Oktober 2019).

Pendapat dari beberapa peserta yang dirujuk secara online Awal-awalnya mereka belum paham dengan rujukan online itu apa, apa maksudnya mereka nggak ngerti dulu tu meskipun udah dikasih sosialisasi oleh orang BPJS dan Puskesmas tapi tetap aja belum paham dengan rujukan online itu apa, dalam sosialisasi itu ada dijelaskan kepada mereka, apa rujukan online itu, manfaatnya apa tujuannya itu apa, tapi yang mereka rasakan masih ada kok manfaat rujukan online itu yang belum terjalankan seperti mengurangi antrian dirumah sakit buktinya mereka masih ngantri dirumah sakit, selain itu misalnya kalau dari segi pelayanan dokternya menurut mereka masih masih kurang nah itu yang menyebabkan menunggu antrian yang agak lama.(hasil wawancara dengan sisra meldawati, deswarni, dan abu nawas pada 08 oktober 2019 dan elmanita, supriyanto pada 09 oktober 2019).
Dari temuan diatas, dapat dipahami bahwa kurang sesuai dengan indikator yang dikembangkan oleh Sutrisno (dalam pertiwi:4) tentang pemahaman program. Yang mana pemahaman program dari efektivitas rujukan online ini belum bisa dikatakan sepenuhnya dipahami oleh masyarakat walaupun ada beberapa cara yang dilakukan oleh BPJS Kesehatan kota solok dalam mensosialisasikan sistem rujukan online ini, namun masyarakatnya juga belum bisa paham dengan program ini, itu yang menjadi kendala oleh BPJS Kesehatan kota solok saat sosialisasi diberikan namun masyarakat belum semuanya paham dengan program sistem rujukan online.

\section{Tepat Sasaran}

Ini dapat dilihat dari sejauh mana apa yang dikehendaki dapat tercapai atau menjadi kenyataan. Ini dapat dilihat dari ungkapan pendapat EVD (Kepala Bidang Penjaminan Manfaat Primer (PMP) BPJS Kesehatan Cabang Kota Solok) mengungkapkan bahwa :

"Rujukan online ini pertama sekali kita tujukan kepada peserta kita yaitu peserta JKN-KIS, kemudian kita tujukan kepada FKTP, dan kemudian kita tujukan kepada FKRTL. Program rujukan online sudah tepat sasaran kepada peserta yaitu dengan tujuan agar peserta mendapatkan manfaat pelayanan kesehatan yang lebih tepat ini dapat dilihat ketika masyarakat diberikan pelayanan di FKTP dia membutuhkan pelayanan lanjutan maka dia diberi pelayanan lanjutan sesuai dengan kebutuhannya dan itu kalu menurut kami sudah benar".(wawancara, 08 Oktober 2019).

Kemudian DP (Staf P Care Kesehatan Puskesmas Tanjung Paku) mengungkapkan bahwa : 
"Udah itu tergantung dokternya rujukan itukan gunanya untuk faskes kalau kita nggak bisa menangani disni kita rujuklah ke faskes yang lebih tinggi itu tergantung dokternya ya, selama ini sesuai dengan tujuan poli yang mana sesuai dengan keluhannya, terkadang dipihak rumah sakitnya yang bermasalah yaitu sistem Rujuk Baliknya".(wawancara 09 oktober 2019). Begitu pula dengan $M$ (Kepala Instalasi

Rekam Medis RSUD Muhammat Natsir) mengungkapkan bahwa :

"Bentuk pelayanan sasaran
jaminan kesehatan nasional rujukan
online ini sudah sesuai dengan SOP
kami jalankan, contohnya kayak
penyakit komankol, influenza,
demam biasa ja kan nggak harus ke
FKRTL itu bisa di FKTP gitu,
kecuali obat-obat yang kronik baru
bisa dirujuk gitu seperti diabetes
mellitus, stroke, jantung, hipertensi,
psikiatri atau penyakit jiwa, asma,
epilepsibisadiPRB kanke kitagitu,
misalnya kalu udah stabil
penyakitnya disni harus kita
balikkan ke asalnya ke FKTP nya,
kemudian BPJS selalu
mensosialisasikan aturan terkait
PMK atau perubahan PMK,
undang-undang atau regulasi
tentang SOP perubahan BPJS
aturan, pokok nya semua aturan
yang ada perubahan dia selalu
mensosialisasikan kepada kita
dengan mengundang kita seperti
manajemen yang
terkait”.(wawancara 08 oktober
2019).

Pendapat dari beberapa peserta, mengatakan bahwa mereka kalau pelayanan rujukan online ini sudah bisa dikatakan baik kan di aplikasinya saat mereka dirujuk sudah ditentukan dokter nya siapa yang akan melayani dirumah sakit nantik, nah itu kalau masalah keluhan mereka ada yaitu mereka nggak bisa menentukan langsung mana rumah sakit yang mereka suka misalnya kalau dari segi pelayanan rumah sakit masih kurang karena menurut mereka masih menunggu antrian yang lama, kan bosan mereka jadinya.(hasil wawancara dengan sisra meldawati, deswarni, dan abu nawas pada 08 oktober 2019 dan elmanita, supriyanto pada 09 oktober 2019).

Hal diatas, sudah sesuai dengan indikator mengenai tepat sasaran yang dikemukakan oleh Sutrisno (dalam Pertiwi:4)yang mana pada kenyataan yang terjadi peserta sudah mendapatkan kepastian waktu pelayanan dengan kompetensi dan radius terdekat dan juga peserta sudah mendapatkan pelayanan yang sesuai dengan kebutuhan medisnya, namun maanfaat nya yang satu lagi belum bisa dirasakan oleh pasien karena masih terdapatnya penumpukan pasien dirumah sakit karena menunggu antrian yang lama disebabkan oleh tenaga medis yang kurang memadai.

\section{Tepat Waktu}

Yaitu dapat dilihat melalui penggunaan waktu untuk pelaksanaan program yang telah direncanakan tersebut apakah telah sesuai dengan yang diharapkan sebelumnya, ini dapat dilihat dari ungkapan kutipan EVD (Kepala Bidang Penjaminan Manfaat Primer BPJS Kesehatan Cabang Kota Solok) mengungkapkan bahwa :

"Rujukan online sudah efektif
karena memang sudah sesuai
dengan tujuan nya yaitu untuk
memberikan pelayanan kepada
masyarakat sesuai dengan
kebutuhannya, namun masih
terdapat kendala dalam
pelaksanaannya yaitu seperti
kendala di Aplikasi karena belum
sesuai dan juga ada kendala dari
peserta yang masih belum paham
terkait dengan rujukan online
ini.terkadang masih ada dari


peserta ketika rujukan online dia dirujuk ke Rumah Sakit terendah dahulu sesuai dengan kebutuhannya malahan dia memintak untuk dirujuk ke Rumah Sakit yang paling tinggi yang seharunya dia dirujuk ke Rumah Sakit terendah terlebih dahulu, nah itu itu masih banyak masyarakat yang terkendala di FKTP". (wawancara, 08 oktober 2019).

Kemudian pendapat E (Staf P Care Kesehatan Puskesmas Tanah Garam) mengungkapkan bahwa :

"Rujukan online disni belum semuanya dikategorikan efektif karena kita melihat masih ada beberapa kendala dan keluhan. kalau kendala yaitu dari apalikasi nya kadang jaringannya yang bermasalah. misalnya kalau keluhan yaitu dari pasien, pasien tidak bisa memilih secara langsung mana rumah sakit yang dia mau karena secara otomatis aplikasi yang menentukan, dan ada juga pasien yang mengeluh karena pelayanan dirumah sakitnya agak kurang, baik itu dari segi fasilitas, tenaga medis maupun sarana dan prasarana".(wawancara, 09 juli 2019).

Berdasarkan pendapat dari beberapa peserta rrujukan mengatakan bahwa Menurut mereka rujukan online ini ada bagusnya ada nggak nya, kalau bagusnya layanan nya cepat, pasti, menghemat ia juga tapi kalau nggak nya yaitu itu pada saat mereka dirujuk mereka tidak bisa memilih secara langsung mana rumah sakit yang mereka suka karena secara langsung dirujuk otomatis oleh aplikasi.(hasil wawancara dengan sisra meldawati, deswarni, dan abu nawas pada 08 oktober 2019 dan elmanita, supriyanto pada 09 oktober 2019).

Hal diatas, belum sesuai dengan indikator yang dikembangkan oleh Sutrisno yang mana untuk ketepatan waktu bisa dilihat melalui penggunaan waktu untuk pelaksanaan program yang telah direncanakan tersebut apakah telah sesuai dengan yang diharapkan sebelumnya, namun pada kenyatannya program ini belum bisa dikatakan efektif karena ada beberapa faktor kendala maupun keluhan yang dirasakan oleh peserta dalam menjalankan rujukan online ini.

\section{Tercapainya Tujuan}

Ini dapat dilihat melalui pencapaian tujuan program yang sudah dijalankan atau dilaksanakan. Ini dapat dilihat dari ungkapan pendapat EVD (Kepala Bidang Penjaminan Manfaat Primer BPJS Kesehatan Cabang Kota Solok) mengungkapkan bahwa :

"tujuan dari rujukan online ini sudah tercapai bisa dikatakan sudah berjalan dengan baik 80-90 $\%$ an lah, karena kami BPJS Kesehatan punya SOP (Standar Operasional Prosedur) yang ditetapkan kepada kami dan itu SOP yang kami laksanakan yaitu panduan kami dalam melaksanakan rujukan online dengan melihat kondisi di Indonesia pada waktu rujukan online ini berjalan".(wawancara 08 oktober 2019).

Kemudian ES (Pra Penyelihan Puskesmas KTK) mengungkapkan bahwa:

"Mungkin kalau tujuan dari rujukan online ini sudah tercapai ya karena kita merujuk pasien itu sesuai dengan kebutuhan penyakitnya dan juga pelayanan yang kita berikan bagi kita sudah sesuai dengan SOP yang ditetapkan BPJS Kepada kita".(wawancara, 09 Oktober 2019).

Berdasarkan pendapat dari beberapa peserta mengatakan bahwa : Kalau pelayanan dalam rujukan online ini sudah 
bagus, kan mereka pada saat datang kepuskesmas untuk berobat terlebih dahulu mereka kan diperiksa oleh dokternya untuk mengetahui penyakit apa yang mereka derita, kemudian mereka dirujuk ketempat mana mereka seharusnya sedangkan Kalu dari segi pelayanan dalam rujukan online itu dirumah sakit belum bisa dikatakan bagus lah karena mereka nggak sepenuhnya bisa merasakan manfaat diadakannya rujukan online ini seperti mengurangi antrian pada rumah sakit, yang mereka rasakan masih melihat ada penumpukan dirumah sakit pada saat dirujuk kesana.

\section{Perubahan Nyata}

Dapat diukur melalui sejauhmana program atau kegiatan tersebut dapat memberikan suatu dampak atau efek serta perubahan yang nyata kepada masyarakat atau peserta ditempat. Ini dapat dilihat dari ungkapan DP (Staf P Care Kesehatan Puskesmas Tanjung Paku) mengungkapkan bahwa :

"Selama menjalankan rujukan online masih ada keluhan dari pasien yaitu mengenai jadwal dokternya yang tidak tersedia dirumah sakit, terkadang pasien itu nggak harus dirujuk tetapi dia mintak dirujuk juga, namun dengan adanya rujukan online ini pasien sudah mendapatkan pelayanan kesehatan sesuai dengan kebutuhannya walaupun masih ada juga keluhannya".(wawancara, 09 oktober 2019).

Kemudian E (Staf P Care Kesehatan Puskesmas Tanah Garam) mengungkapkan bahwa :

\footnotetext{
"Kalau dilihat dari keluhan pasien masih ada keluhan seperti ketika pasien mau dirujuk, dia maunya dirujuk kerumah sakit yang ini, tetapi didalam aplikasi dia tidak dirujuk kesitu malahan kerumah sakit yang lain dia dirujuk, namun dengan adanya rujukan online ini
}

pasien bisa mendapatkan pelayanan sesuai dengan kebutuhannya".(wawancara, 09 juli 2019).

Kemudian berdasrkan pendapat dari peserta yang dirujuk secara online, mereka mengatakan bahwa : Kalau rujukan online ini dengan rujukan sebelumnya bisa dikatakan baik lah dalam proses rujukan online karena mereka dirujuk sesuai dengan kebutuhan penyakit yang mereka alami, dengan rujukan online mereka nggak perlu membawa kertas print lagi kerumah sakit karena data mereka ini sudah dikirim ke rumah sakit, beda dengan rujukan sebelumnya atau rujukan manual iya mereka dikasih kertas oleh petugas puskesmasnya untuk berobat kerumah sakit.

Hal diatas belum bisa dikatakan sesuai dengan indikator yang dikembangkan oleh Sutrisno yaitu mengenai perubahan nyata. Yang mana perubahan nyata tersebut bisa diukur melalui sejauhmana kegiatan tersebut memberikan suatu efek atau dampak serta perubahan nyata bagi masyarakat setempat. Kenyataan yang terjadi dengan adanya program ini masyarakat atau peserta masih mempunyai keluhan yang sudah dijelaskan diatas, tetapi dengan adanya rujukan online peserta sudah bisa juga dikatakan bisa merasakan beberapa manfaat diadakannya rujukan online ini.

\section{PENUTUP}

Berdasarkan hasil pembahasan, diperoleh untuk menjawab sebuah kesimpulan untuk menjawab rumusan masalah yang telah diajukan dalam penelitian ini adalah tentang efektivitas rujukan online dalam program jaminan kesehatan nasional (JKN) di kota solok. Dalam hal ini efektivitas rujukan online dalam program jaminan kesehatan nasional dikota solok masih belum efektif. Ini dapat dilihat dari beberapa kendala dan juga keluhan yang dirasakan oleh masyarakat atau peserta, seperti kendala yang ditemui 
oleh BPJS Kesehatan kota solok yaitu mengembalikan mindset atau pola piker peserta itu agak susah, dan kendala dari FKTP yaitu kendala dari jaringan saat proses rujukan berlangsung yang dapat mengganggu peserta pada saat proses rujukan yang mengakibatkan peserta harus menunggu untuk beberapa waktu, serta kendala mengenai sistem rujuk balik dari FKRTL tidak jelas. Serta kendala dari FKRTL yaitu pasien yang dirujuk terkadang tidak sesuai dengan penyakit yang dialaminya, contohnya seperti penyakit ada infeksi pada gigi, namun peserta dirujuk kerumah sakit itu kepada poli gigi yang biasa sementara dia lebih membutuhkan pelayanan yang sub spesialis. Sedangkan keluhan dari pasien yaitu peserta masih kurang paham dengan sistem rujukan online ini, bagaimana alur dan juga konsep dari rujukan online ini, serta masih ada peserta yang mengeluh saat dirujuk ke Fasilitas Kesehatan Rujukan Tingkat Lanjut (FKRTL) yang mengeluh karena masih menunggu antrian yang lama diakibatkan karena dokter atau tenaga medis yang akan melayaninya kurang memadai dibandingkan dengan banyaknya peserta yang dirujuk.

\section{DAFTAR KEPUSTAKAAN}

Anas, M. E. S. 2018. "Efektivitas Program Pemberdayaan Umkm Melalui Renstra 2011-2016 (Studi Kasus Pada Disperindagkop Dan Umkm Di Kota Bontang)". eJournal Administrasi Bisnis, 2018, 6 (4) : 1308 - 1320 ISSN 2355-540.

Frinaldi, A, (2017a). "The Influence of Work Culture on Work Performance of employees in Department of Transportation, Communcation and Informatics of West Sumatera" dalam Jurnal Ilmiah Wahana Bhakti Praja Vol.7 No.2. (pp:83-92).

Frinaldi, A, Muhamad Ali Embi. (2011). "Pengaruh Budaya Kerja Etnik
Terhadap Budaya Kerja Keadilan dan Keterbukaan PNS dalamMembangun Masyarakat Madani dan Demokrasi (StudiPada Pemerintah Kabupaten Pasaman Barat)" dalam Jurnaldalam Jurnal Humanus Vol.13 No.1. (pp:6875).

Pertiwi,M.Nurcahyanto,H.Efektivitas

Program Bpjs Kesehatan Di Kota Semarang (Studi Kasus pada Pasien Pengguna Jasa BPJS Kesehatan di Puskesmas Srondol). Fakultas Ilmu Sosial dan Ilmu Politik Universitas Diponegoro.

Primasari, K, L. 2015 "Analisis sitem rujukan Jaminan Kesehatan Nasional RSUD. Dr Adjidarmo kabupaten lebak". Jurnal Administrasi Kebijakan Kesehatan Volume 2 Februari 2015.

Robi Cahyadi Kurniawan.2016. Inovasi Kualitas Pelayanan Publik Pemerintah Daerah. Fiat Justisia Journal of Law ISSN 1978-5186Volume 10 Issue 3, July-September 2016.

Wardani, R, K. 2014. Analisis Penetapan Prioritas Program Upaya Kesehatan Dasar (Puskesmas) Pada Tingkat Pemerintah Daerah (Studi Eksploratif Di Kota Bogor Tahun 2013). Jurnal Kebijakan

Undang-Undang No 24 Tahun 2011 Tentang Badan Penyelenggara Jaminan Sosial (BPJS).

Undang-Undang No 44 Tahun 2009 Tentang Rumah Sakit 